\title{
SOBRE LOS DEMOSTRATIVOS: ORÍGENES Y EVOLUCIÓN
}

\author{
Maristina EGIDO FERNÁNDEZ \\ Universidad de León
}

\section{1.- Los demostrativos en latín}

1.1.- Desde el punto de vista morfológico, el demostrativo latino se caracteriza por mostrar las mismas cualidades que los adjetivos en cuanto a las marcas de género, número y caso, aunque, a diferencia de estos, carece de gradación; además puede aparecer sustantivado o "funcionando como pronombre"' (de ahí la denominación de pronombres demostrativos por parte de muchas gramáticas tradicionales). Desde el punto de vista sintagmático, se caracterizan, en palabras de Tordan-Manoliu": "por la posibilidad de acompañar como determinantes a un sustantivo o llevar un determinante adjetival en el caso de que desempeñen función de pronombre".

Semánticamente tienen, sobre todo, un valor deíctico, es decir, en un acto de elocución concreto, sirven para situar al referente del sustantivo al que acompañan o representan en el espacio (o en el tiempo) circundante de los interlocutores. Este campo deictico, el latin lo subdivide en tres grados relacionados directamente con la triple división del morfema de persona, triple división que, como bien recoge Iso Echegoyen, aunque no se manifiesta en el pronombre personal por ejemplo, sí lo hace en el verbo. ${ }^{3}$

Para señalar lo situado en la esfera de la primera persona -ego- o, tal como lo expresan Bassols y Ernout-Thomas "para indicar lo que esta cerca de la persona que habla, en el espacio, en el tiempo o en su espíritu", se utiliza el demostrativo hic, haec, hoc; asi:"

Ihic liber ("Este libro, el libro que tengo en mis manos").

lic dies ("Este día, el día de hoy").

llac fabula ("Esta comedia, la comedia que ahora representamos").

1 Así suele aparecer explicado en los tratados tradicionales el hecho de que tenga la capacidad de apnrecer autónomamente cumpliendo las funciones propias de un sustantivo. La expresión "funcionar como un pronombre" go es adecunda puesto que "pronombre" es una categoría semántica y no funcional.

2 IORDAN, I.-MANOLIU, M. (1972); Manual de Lingüistica románica, I-II, Madrid, Gredos, peig. 300 (citado IORDAN- MANOLIU (1972)).

${ }^{3}$ ISO ECHEGOVEN, J J. (1974); "En torno al sistema déictico pronominal en latín y su paso a las lenguas románicas", R.E.L., 4/2, 459-471, paig. 46.5 (citado I. ECIIEGOYEN (1974)).

* BASSOLS DE CLIMENT, M. (1981); Sintaxis latina, I-[I (1956), Madrid. C.S.I.C., págs. 199-209 (citado BASSOLS (1981)). ERNOUT, A. TIOMAS, F. (1972): Symlaxe latine (1953), Paris, Klincksieck, paigs. 187-190 (cilado ERNOUT- TIIOM $\Lambda$ S (1972)). 
Iste, ista, istud se utiliza para señalar los objetos o circuntancias situados en la esfera del interlocutor:

Iste liber (“Ese libro, el libro que tienes en tus manos").

Noobstante, Bassols señala que este demostrativo presenta una relación mucho menos estrecha con la segunda persona que la que muestra el anterior con la primera, de ahi que pueda aparecer reforzado con los correspondientes posesivos, como en este ejemplo de Plauto: Ex istac tua sorore (lit. "de esa tu hermana"); y que, incluso, pueda referirse a una tercera persona (Terencio: Id isti vituperant (lit "esos denigran esto")), o a aquello que está cerca de la persona que habla (iste liber = hic liber).

Finalmente, para todo lo que se considera englobado en la esfera de lo que no es primera ni segunda persona -es decir, la tercera persona- se utilizaba ille, illa, illad:

Haec urbs est Thebae: in illisce habitat aedibus Amphitruo (Plauto, Bouvier (1972), 75) ("Esta es la ciudad de Tebas: en aquellas casas vive Amphitruo").

\begin{tabular}{|c|c|c|}
\hline$e g o$ & $t u$ & no $e g o /$ no $t u$ \\
\hline HIC & ISTE & ILLE \\
\hline
\end{tabular}

Además de este valor deíctico, pueden tener también valor fórico, especialmente hic e ille. Hic puede reproducir algo que acaba de decirse:

Diem, aquam, solem..., haec argento non emo (Plauto).

("La luz (el día), el agua, el sol...estas cosas no las compro con dinero").

Tambiên puede enunciar lo que va a decirse como en: Venit hoc mihi, Megadore, in mentem (Plauto)("Se me ocurre esto, Megadore"), donde hoc hace referencia clara a algo que se dirá a continuación.

C. Codoñer señala que en Plauto o Cicerón, los usos fóricos de hic (lo mismo anafóricos que catafóricos) aluden siempre a elementos enunciados por la persona que está hablando ("hacen hincapie en la materia gramatical creada por el hablante partiendo de la realidad"), aunque no es posible determinar si se trata de un valor generalizado en latín clásico que diferencia el uso de hic como fórico del resto de los fóricos."

Ille, con este valor, puede denotar lo ya mencionado o conocido con cierta anterioridad:

Factum est illud (Plauto) ("Se hizo aquello").

5 BOUVIER. [. (1972): "Le demonstratif ]utin ille eL la formation de l'article détini des langues romanes", Cahiers de Lexicologie, 21, 2, 75-86 (citado BOUVIER (1972)).

${ }^{6}$ CODOÑER, C. (1973); "Introduccion al estudio de los demostrativos latinos", R.E.L., 3/1, 81-93, prigs. 85-90 (citado CODOÑEH (1973)). 
Lo que acaba de mencionarse: ${ }^{7}$

Me salutauisti, et ego te, et osculum tetuli tibi.

Iam illud non placet principium de osculo (Plauto)

("...me has saludado, y yo a tí, y te he dado un beso.

Lo cual (lo del beso), en principio, ya no me gusta").

Asimismo aparece con lrecuencia antepuesto o pospuesto al nombre de una persona o un objeto universalmente conocido: Ille Demosthenes; Medea illa, etc.

Iste, en cambio, apenas aparece con valor lórico y, generalmente, sólo para reproducir un concepto mencionado por el interlocutor (istud faciam "eso (que tú pides) haré").

Tenemos, pues, como una primera apreciación, que en los demostrativos latinos la reforencia del morlema de persona está mucho mảs definida en el caso de hic e ille que en el de iste. Este último, con una referencia menos estricta, puede llegar a los campos que, en principio corresponden a los otros dos elementos del sistema.

Este sistema ternario se mantuvo esencialmente inalterado en gran parte de la historia del latín.

Sin embargo, algunos de los estudios realizados sobre obras de distintas épocas muestran que los valores de ese sistema no eran siempre tan untformes. Por ejemplo, $A$. Fontún señala que ya en ẻpoca de Cicerón, luera de contextos peyorativos e irónicos, "apenas si se puede ya emplear iste para la segunda persona"; el sistema deictico propiamente dicho, se apoya más en hic e ille indicando "proximidad fisica"/ no proximidad' respecto del hablante."

I.2.- Al lado de estas tres lormas que componen los demostrativos propiamente dichos, existen otras con valor muy cercano y con las que no es extraño que confluyan hic, iste, ille. Se trata del anafórico is, y de los llamados pronombres de identidad idem e ipse.

Is, ea, id, usado como adjetivo o sustantivado, tiene un valor puramente anafórico o "de reenvío", es decir, hace referencia a algo conocido por el emisor y el receptor del mensaje pero cuya posición en el espacio no se quiere precisar:

Erat comes eius Rubrius quidam... is ad eum rem istam defert (Cic.).

("Tenia por compañero a un tal Rubrius...éleste (Rubrius) le trae lo siguiente (esta cosa)").

Ea res est Helvetiis nuntiata (Caes.).

("Esta cosa/esto (en todo caso, algo previamente mencionado) es anunciada(o) a los Helvetios").

7 Y, según Bassols ((1981), 201), también lo que sigue, aunque I. Eehegoyen ((1974), 464), por ejemplo, niega una función catafórica de ille.

"FONTAN, A. (1965); "Historia y sistemas de los demostrativos latinos", Emérila, XXXIt1/1, 71-107, püg. 94 (citado FONTAN (1965)). 
Idem, eadem, idem (compuesto del anafórico is més la partícula -dem) tiene el valor de reforzar la idea de 'identidad', por ello aparece con frecuencia en usos pleonísticos unido a otro pronombre: hic idem; ille idem, etc.

Ipse, ipsa, ipsum, etimológicamente, según señalan Bassols y ĖrnoutThomas, signilica "él, y ningún otro"; en latín señala, pues, una idea de oposición expresa o latente "él, por oposición a otro presente o no":

Ipse Caesar.

("César, êl mismo y no otro").

Ualuae... se ipsae aperuerunt.

("Las puertas se abrieron por ellas mismas (y no por otra fuerza)").

Además de la semejanza formal con los domostrativos, la razon por la que siempre se sucle incluir a idem e ipse junto a estos es que pueden cubrir también valores anafóricos, especialmente idem, que hace alusión, por lo regular, a algo ya mencionado o conocido, pero también, en determinadas construcciones, puede aludir a lo que va a decirse)., ${ }^{\text {" }}$

II.- Latin tardio y vulgar. El sistema protorromance

II.1.- En el latín tardío y vulgar se registran una serie de usos anómalos respecto de la norma del latín clásico que, como en otros muchos aspectos, no hacen sino apuntar evoluciones que acabarán consolidaindose en romance.

A. Fontán señala como general en la prosa postclásica, la de Séneca, por ejemplo, el poco uso de $i s t e$ referido a la segunda persona fuera de contextos peyorativos, algo que ya se adelantaba en Cicerón. En contextos no peyoralivos, se observa cada vez más claramente el uso de iste como sinónimo de hic, como en las equivalencias hoc affectu tuo, isto tuo uulnere ("con este tu afecto, con este tu dolor") presentes ya en Séneca. Se relleja además, do forma muy clara, la reducción del uso de is y la penetración muy acusada de los deícticos hic y, sobre todo, ille en el campo puramente anafórico ${ }^{116}$. Ernout-Thomas recogen varios ejemplos:

Multos Fortuna quos supsttulit alte, hos (=cos)...premil (Pompeya, C.I.L.).

("A muchos que la Fortuna ha alzado, (ella misma) los vuelve a hundir").

Habuit...oracularios seruos qui illum $(=\mathrm{cum})$ pessum dederunt.

("Tenía por oráculos a algunos esclavos que le levaron a la perdición (lit. que le dicron pesar)).

Hos (= eos)...deus quos probat...exercet (Séneca).

("Dios prueba a los que ama").

Quod illi (= ei) difficillimum est cui...placent...

("Algo muy difícil para un hombre a quien gustan...").

En la prosa posterior a Séneca todas estas tendencias so harán generales. La desaparjeión de is, ea, id es un hecho claro hasta el punto de que su presencia en ciertos textos y autores como la Vulgata o S. Agustín es indicio

"BASSOLS (1981), paig. 204

10 FONTAN (1965), pág. 102 
de una expresa voluntad y calidad literarias.

También son patentes la tendencia a la desaparición de idem quedando reducido a usos pleonásticos, muy frecuentes en latín tardio $y$, aunque de forma menos perceptible, los desplazamientos en el uso de ipse. Es relativamente frecuente en los textos latino-vulgares el uso de ipse con valor puramente anafórico, sustituyendo al is clúsico, o con valor deíctico como en este ejemplo de la Peregrinatio:"

Requisiui de eo quam longe esset ipse locus.

("Le pregunté a qué distancia se encontraba ese lugar").

Ipse tiende a perder su sentido originario de identidad para adquirir un valor fórico o convertirse en algo cercano at un demostrativo, aunque en principio sin una referencia situacional clara.

\begin{tabular}{|l|l|l|}
\hline$[$ HIC & - ISTE & ILLE \\
\hline & & \\
\hline
\end{tabular}

Los cambios que se producen en el seno de este paradigma son explicados por autores como Wartburg, Vaiänänen, 1. Echegoyen o V. Lamiquiz, como alteraciones en cadena del equilibrio del sistema producidas por el desplazamionto de una forma que arrastra a otra, $y$ así sucesivamente ${ }^{12}$. En el proceso que describen Wartburg o Lamiquiz, por ejemplo, es is el punto de partida.

Is, sometido al máximo de desgaste y debilitación fonética y semántica, empiezir a ser sustituido por hic ya en época clásica.

Por su parte, I. Echegoyen atribuye el inicio del proceso al desgaste y progresiva desaparición tanto de is como de hic. Veiamos antes que, aunque hic en la prosa postclásica se sigue manteniendo tras adquirir el valor puramente anaförico do is, es común que aparezca iste en su lugar. El hecho de que necesite el reluerzo con partículas (honce, hance, huiusce, hasce, etc.) indica que su signilicante posec escasa entidad fónica, al igual que el de is; más aún, una vez que desaparece la aspiración en la época clásica, el paradigma de hic tenderá a conlundirse con el de is, conlusión a la que contribuyen los cambios en el vocalismo del latín vulgar (por ejemplo dat. y ablat. pl. his/iis; nom. pl. hi/ii). La distinción formal entre ambos en

" l:ONTAN (1965), pág. 104.

${ }^{12}$ WAITTBURG, W. v. (1951); Problemas y mélodos de la lingüistica (1943'), CSIC, Madrid (2a ed. on colab. S. Ullmann, Einfhrung in Problematik und Methodik der Sprachwissensch, 'l'ubinga, 1962), págs. 235-40 (citado WARTBUnG (1951)). VÄANÄNEN, V. (1975); Introducción al latín vulgar (19671), Madrid, Gredos, pág. 269-74 (citado VÄÄNÄNEN (1975)). LCHEGOYEN (1974), 467-8. LAMIQUIZ, V. (1967); "El demostrativo en español y en Irancés: estud io comparativo y estructuración", R.F.E. L, 163-202, \& 2.1 (citado LAMfQUIZ (1967)). 
esas condiciones resulta imposible por lo que, finalmente ambos desaparecerán como formas autónomas.

Una vez desaparecido hic - además de $i s-$, quedan dos únicos elementos, iste e ille para expresar todo el campo deíctico. A. Fontán señala que a partir de prosistas como Valerio Máximo o Quinto Curcio se puede hablar ya de ese sistema bipartito iste/ille en el que el valor de hic lo expresa iste.

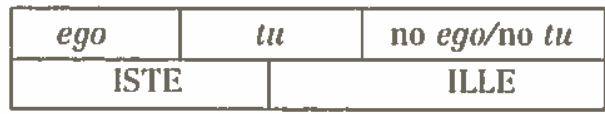

En efecto, este cambio es especialmente perceptible on las inscripciones del latín vulgar sobre lápidas. Díaz y Diaz recoge: ${ }^{13}$

IIt sub ista labidem marmorea, quem Vector ver inluster preses ordinabit venire de Triento, hic requiescit...

("Aquí, bajo esta ("haec') lápida de mármol(...) aquí descansa...").

A. J. Carnoy en inscripciones hispánicas de la época precristiana y cristiana registra: Ista terra sit ((ibi) ((evis)(“Esta tierra te sea ligera"); Isto monumento ("En este monumento"); Transitus iste ("Este paso"); Sefronius tegetur tomolo antestis in isto ("El obispo Sefronius estä enterrado en este túmulo (tumba)"14.

Ahora bien, iste/lle no se mantienen inalterables en sus valores, especialmente ille que, al desaparecer is y quedar vacia la expresión de la fóresis tan viva en el latín anterior, pasará a rellenar inmediatamente esta casilla; nada extraño, por otro lado, si recordamos la fuerte tendencia de ille en el latín literario a la función förica (en competencia con is) debido a que era el deíctico menos marcado en cuanto al morfema de persona (hacía referencia a todo lo alejado de la esfera del yo y del túl. ${ }^{15}$

${ }^{13}$ DIAZ Y DLAZ, M. (1962); Antologia del latin vulgar, Madrid, Gredos, pëg. 133 (citado DIAZ Y DIAZ 1962).

it CARNOY . A.J. (1983); Le latin d"Espagne d'après les inscriptions (1906'), Hildesheim, Georg Olms, päg. 248 (citado CAlnNOY (1983)).

${ }^{15}$ A partir de esta especialización como fórico de ille surgen sus nuevos valores, ya romances, como pronombre personal de tercera persona y como artículo; dos calogorias que desconocía el latín clásico y que, sin embargo poseen las lenguas romances (aunque no en todas procedentes de ille). Aunque la aparicion de estas dos nuevas categoríts romances es un tema directamente relacionado con el que aquí desarrollamos, se trata de un aspecto complejo que nos desviaria del contenido central del mismo. Por ello no entraremos a analizar en profundidad todas las circunstancias tanto internas como externas a la lengua que propiciaron su aparición. Existen multitud de esitudios que, desde principios de este siglo, Intentan explicar, desde diversas ópticas, por qué surgíeron las nuevas formas y el imbricado proceso por el que ille (ipse) fuo transformeindose hasta alcanzar ambos valores (Vid. por ej. ABEL. F. (1971); L'adjectif démonstratif dans la langue de la Bible Latine. 


\begin{tabular}{|c|c|c|}
\hline ego & $t u$ & no ego/no $t u$ \\
\hline ISTE & \multicolumn{2}{|c|}{ ILLE (eccille) } \\
\hline ILLE & & IPSE \\
\hline \multicolumn{3}{|c|}{ "Fóricos" } \\
\hline
\end{tabular}

II.2.- En definitiva, todos estos cambios que se observan en ol latín vulgar acabarain desembocando en las diversas tendencias del diasistema deíctico protorromance, diasistema del que lógicamente hay que partir para explicar los resultados de las lenguas romances.

Electivamente, los datos que se desprenden de la comparación de los resultados romances ${ }^{16}$, indican que, en una parte de la Romania se generalizaría la tendencia a un sistema binario con la oposición "proximidad" / 'lejania' (iste/ille) con respecto al acto del discurso, sin tener en cuenta el morfema de persona con la triple oposición utilizada por el latín.

Ahora bien, para los resultados que se dan en esá zona no es posible partir directamente de iste/ille como tales lormas. Esos datos demuestran que, una vez que ille se especializa en expresar la fóresis, ocupando la antigua casilla de is, va a dejar vacia momentáneamente la del tercer elemento de la seric deíctica y para completarla, la lengua recurrirả a uno de los dobletes estilísticos con los que contaba ya desde época antigua para señalar la deixis relorzada: eccille quedará (por oposición al fórico ille) como pura deixis en su tercer grado ${ }^{17}$ :

Etude sur la formation des systèmes déictiques et de l'article défini des langues romanes, Beihefte zur Zr, Ph 125. 'Tübingen, Niemoyer'; AEBISCHER, P. (1948); "Contribution ì la protohistoire des articles ille et ipse dans les langues romanes", Cullura Neolatina, VIII, 181-203; GAMILLSCIHEG, E. (1937); "Zur romanischen Artjkel und Possessivpronomon", En E. Gamillscheg Ausgewählle Aufsälze, JenaLaipzig, W. Gronau, 43-78; LERCH, E. (1940): "Gibt es im Vulgärtat. odor im Rimän. eine "Gelenkspartikel",ZhPh, LX, 113-190; LÖFSTEDT, E.(1942); "Zur Vorgeschichte des romanischen Artikels", Syntactica, I, cap.XIX, Lund-Leipzig-London; TRAGEH, G.L. (1932); The use of the latin demonstratives (specially "ille" and "ipse") up to 600 a.D. as the source of the Romance article, New York: Whнтвuн (1951), atc.).

16. En ningún caso su consorvan resultados de hic como forma autónoma aunque pudo mantenerse combinado con otras formas (per hocs it. peró; hoc annos cast.ant. hogaño. etc.)

${ }^{17}$ ECHLGOYLN (1974), pág. 467 


\begin{tabular}{|c|c|}
\hline \multicolumn{2}{|c|}{ Acto de habla } \\
\hline "Proximidad" & "Lejanía" \\
\hline ISTE & ECCILLLE \\
\hline
\end{tabular}

Como lenguas romances que poseen un sistema deíctico binario ('proximidad'/lejanía') tenemos el rumano, con resultados acesta/acela procedentes ambos de formas reforzadas (a partir de iste/ille) por la partícula ecce; y el franceis, que ni siquiera mantiene cercano el significado originario, ya que los resultados de (ecce)ille (celui-ci/celui-là) son los de uso pronominal, mientras que los de iste, también reforzados por ecce (ce-ci/ce-lả), son usados como adjetivos.

\begin{tabular}{|c|c|c|}
\hline & "Proximidad" & "Lejania" \\
\hline RUMANO & $\begin{array}{c}\text { acesta } \\
\text { (<ecce-iste) }\end{array}$ & $\begin{array}{c}\text { acela } \\
\text { (<ecce-ille) }\end{array}$ \\
\hline FRANCESS & $\begin{array}{c}\text { ceci (advo.) } \\
\text { (<ecce-iste) } \\
\text { celui-ci (prbre.) } \\
\text { (<ecce-ille) }\end{array}$ & $\begin{array}{c}\text { ce-là (advo.) } \\
\text { (<ecce-iste) } \\
\text { celui-là (prbre.) } \\
\text { (<ecce-ille) }\end{array}$ \\
\hline
\end{tabular}

En otra amplia zona de la Romania la tendencia que se generalizó fue la de crear sistemas deícticos de tres grados. La influencia paradigmática de la triple distinción personal presente en el paradigma verbal o el posesivo, entre otras posibles causas, debieron cjercer una fuerza importante en algunas lenguas para que se reinstauraran, como en latín, sistemas ternarios, distribuidos según la triple distinción del morfema de persona.

En este grupo se encontrarian todas las de la P. Ibeirica (ptg. este, esse, aquele; cast. este, ese, aquel; cat. aquest, aqueix, aquell, etc.), además del italiano (questo, codesto, quello) y el sardo (custe, cusse. icctdde). ${ }^{16}$ 


\begin{tabular}{|c|c|c|c|}
\hline & YO & TU & EL \\
\hline ESPAÑOL & $\begin{array}{c}e s t e \\
\text { (<iste) }\end{array}$ & $\begin{array}{c}\text { ese } \\
(<\mathrm{ipse})\end{array}$ & $\begin{array}{c}\text { aquel } \\
\text { (<eccu-ille) }\end{array}$ \\
\hline PORTUGUES & $\begin{array}{c}\text { este } \\
\text { (<iste) }\end{array}$ & $\begin{array}{c}\text { esse } \\
\text { (<ipse) }\end{array}$ & $\begin{array}{c}\text { aquele } \\
\text { (<eccu-ille) }\end{array}$ \\
\hline CATALAN & $\begin{array}{c}\text { aquest } \\
\text { (<eccu-iste) }\end{array}$ & $\begin{array}{c}\text { aqueix } \\
\text { (<eccu-ipseu) }\end{array}$ & $\begin{array}{c}\text { aquell } \\
\text { (<eccu-ille) }\end{array}$ \\
\hline ITALIANO & $\begin{array}{c}\text { questo } \\
\text { (<eccu-istu) }\end{array}$ & $\begin{array}{c}\text { codesto } \\
\text { (<eccu-id-istu) }\end{array}$ & $\begin{array}{c}\text { quello } \\
\text { (<eccu-illu) }\end{array}$ \\
\hline SARDO & $\begin{array}{c}\text { custe } \\
\text { (<eccu-iste) }\end{array}$ & $\begin{array}{c}\text { cusse } \\
\text { (<eccu-ipse) }\end{array}$ & $\begin{array}{c}\text { iccudde } \\
\text { (<eccu-ille) }\end{array}$ \\
\hline
\end{tabular}

En ninguno de estos casos, en cambio, el sistema es heredero directo del latino clásico: en italiano, además del reluerzo generalizado, son resultados de iste los que. ocupan las casillas del primer y segundo grado de la deixis (codesto<eccum+id+istum); ol área ibérica, en cambio, muestra ya peculiaridades importantes desde el propio latin.

A Carnoy señala que en las inscripciones hispanicas el uso de ipse es mís abundante que en otras zonas y que, desde un principio, se le puede encontrar en lugar de ille o hic, con un valor deictico ${ }^{19}$ :

Set per genus ipsorum (=illorum) posessio decurret...('Tarragona).

("Pero las posesiones pasan por la lamilia de aquellos")

Ex testamento ipsius (= eius) (Lusitania).

("...de el testamento de el").

Pro locello ipso.

("Por ese pequeño lugar (lugarcillo)").

Asimismo R. Lapesa destaca la importancia del uso de ipse como analórico en la Peregrinatio:21 Nam et ecclesia ibi est cum presbytero. Ibi ergo mansimus in ea nocte. et inde maturius die dominica cum ipso presbytero...coepimus ascendere montes. (“...Pues la iglesia estä con el presbítero. Así pues, nos quedamos alli por la noche y rápidamente el domingo comenzamos a subir la montaña con el presbítero").

Tenemos, pues, que el latín ibérico acudirá, a partir de un determinado momento, al enfático ipse para cubrir la lunción deíctica del clúsico iste; un enliático ipse cuyos usos, como ya indicábamos anteriormente, habian

1*. IORDAN-MANOLIU (1972), pág. 302.

19 CAINOY (1983), págs. 247-248.

20 I.AP'LSA, R. (1961); "Dal demostrativo ul artículo", N.R.F.II., XV, 23-44, pág. 24 (citado LAPESA (1961)) 
sufrido desplazamientos importantes desde el latín tardjo. Con la inclusión de ipse quedará tambiến cubierta el área menos marcada del campo deictico, lo que podríamos considerar 'no próximo, no lejano', reponiendose así la triple distinción que ya existía en latín.

III.- El sistema deíctico en el romance castellano: origenes y evolución.

III.1.- Como ya hemos señalado en el apartado anterior, si bien el latín y el castellano tienen la misma triple đistribución relacionada con la triple distinción del morfema de persona, no puede decirse que el sistema castellano sea heredero directo del latino.

El sistema deíctico castellano participó en sus origenes de la misma serie de reajustes y cambios latino vulgares que las demás lenguas romances, reajustes que aquí sólo resumimos puesto que han sido tratados ya en profundidad: a) desaparición de hic; b) desplazamiento de iste del segundo grado de la deixis al primero; c) inclusión de un elemento (ese) que cubre el segundo grado de la deixis que ha dejado vacante iste. Este es el único rasgo en el que el sistema castellano se separa de algunos romances (rumano y (rancés), aunque son mảs los casos de coincidencia (portugués, catalán, italiano, sardo, etc.); d) el resultado de ille presenta el resultado reforzado aquel.

Todos estos cambios, tanto en el signilicente como en el signilicado, impiden que el sistema resultante en castellano, aunque haya llegado a una distribución paralela a la del latín, pueda ser considerado como continuador directo de aquel. Podemos sintetizar el proceso en el siguiente cuadro (los números indican la proximidad o el alejamiento de la función đemarcativa):

\begin{tabular}{|l|l|l|}
\hline HIIC(1) & \multirow{2}{*}{ ISTE(1) } & ESTE(1) \\
\cline { 1 - 1 } ISTE(2) & & ESE(2) \\
\cline { 1 - 1 } ILLE(3) & ILLE(3) & AQUEL(3) \\
\cline { 3 - 3 } & &
\end{tabular}

Avar-Pottier (1983)"1

No obstante, el sistema romance castellano no se estabilizó en el nivel escrito hasta una época muy tardia. Do hecho, en los origenes de nuestra lengua es muy común encontrar usos de los demostrativos con su valor deíctico totalmente debilitado, como parte de fórmulas cuasi gramaticalizadas y sin indicar ningün tipo de precisión situacional, especialmente en el caso de ese como el elemento con función deíctica menos marcada del paradigma. Pero, veamos el comportamiento de cada forma.

${ }^{21}$ ALVAR, M.-POTT]ER, B. (1983); Morfología histórica del español, Madrid, Gredos, pág. 104 (citado ALVAR -P0TTIER (1983)). 
III.2.- Este (esta, esto, estos, estas).

Procedente del paradigma de iste que, una vez desaparecido hic, ha tomado el valor de 'proximidad', desplazándose hacia la 'zona del yo'.

En cuanto a su ovolución formal, la explicación aceptada tradicionalmente (al igual que para ese, y aquel) es que en el singular procede del nominativo y en el plural del acusativo ${ }^{22}$; por su parte, el neutro se diferencia del masculino en el singular y desaparece en el plural:

$\begin{array}{ll}\text { ISTE }>\text { este } & \text { ISTOS> estos } \\ \text { ISTA }>\text { esta } & \text { ISTAS }>\text { estas } \\ \text { ISTUD }>\text { esto } & \end{array}$

La conservación del nominativo para el masculino singular, frente al acusativo en el plural, se explicaría por la necesidad de mantener una distinción clara entre el masculino y el neutro istud, ipsum, illad, puesto que si el origen del primero hubiese sido el acusativo, las formas serían esto, eso. aquello para ambos géneros.

En cambio, para Alvar-Pottier carece de sentido pensar que sólo unas formas parten del nominativo; esto que fonéticamente es posible es morfosintácticamente imposible. El demostrativo concertaba en latín, como en romance, con el sustantivo al que acompaña y si, al desaparecer la flexión casual, el sustantivo va en acusativo, también irá en acusativo el demostrativo. Sería absurdo pretender una concordancia del tipo iste hominem, cuando además el plural era istos homines y no *isti homines. El siguiente paso en esta hipótesis es explicar por qué, partiendo del acus. istum, tenemos hoy en el masculino este y no esto. Avar-Pottier lo explican como un proceso fonético regular: esto (masc.) iba antepuesto al sustantivo y su /-o/ se apocopó como la de otros adjetivos ("buen pan", "pan bueno"; est. esta, esto). Cuando comionzan a considerarse intolerables los finales -st y comienza a generalizarse la reposición de la vocal final, el masculino, a fin de evitar la homonimia con el neutro, tiene que incorporar la /-e/ (única vocal aceptable, por otro lado, puesto que no puede haber $/-\mathrm{i},-\mathrm{w} / \mathrm{la} /-\mathrm{a} / \mathrm{es}$ marca de femenino y la/-o/de netutro); de ahí este. La misma explicación es valida para ese, cuya forma apocopada, además tendía a confundirse con el verbo $\operatorname{ser}^{23}$.

22 Vid. CANO AGUILAR, R. (1988); Rl español a través de los tiempos, Madrid, Arco Libros, púg. 143 (citado CANO AGUILAR (1988); LAPESA. R. (1979); "Nominativo o caso oblicuo latinos como origen do demostrativos y artículo castellanos". $F$. Kurt Baldinger, 196-207, pág. 205 (citado LAPEsA (1979)); LAUSBERG, H. (1964); Lingüística románica. I-11, Madrid, Gredos, pág. 205 (citado IAUSBEHG (1964)); LLOYD, P. (1993); Del latín al español, Madrid, Gredos, pág. 446-47 (citado LLOYD (1993)); MENÉENDEZ PIDAL. R. (1980); Manual de Gramálica histórica española (1940'), Madrid, Espasa-Cajpo, 16² ed., pág. 259 (citado M. Piosl (1980)).

${ }^{23}$ ALVAR-POTTIER (1983), pág. 106. 
Sin embargo, la casuistica de los demostrativos en los documentos más antiguos no parece refrendar claramente esta hipótesis. R. Lapesa recoge ejemplos con $/-0 /$ en el masculino, pero no son menos frecuentes los casos con/-e/y la antigüedad de muchos de ellos, como el de una pizarra visigoda del S. VII, impide pensar en un debilitamiento de $/-0 /$, o en una reposición no etimológica de la vocal final con $/-\mathrm{e} /$ en vez de $/-0 /:^{24}$

“...ste testamentum ei legatur” (Valpuesta, año 864).

"Sic [se] tradidit ste Analso presbiter ad domnu Filimirum episcopum[... ]; et post inde sic dedit ste episcopus sua terra de [regula] ${ }^{*}($ año 911).

"Sic se tradidit sle Fenesterius presbiter sua zella" (año 919).

"Ipse fecit iste arcum" (año 1059).

Los datos que ofrecen los documentos del área riojana conlirman también una procedencia del nominativo, puesto que la /-i/linal de los demostrativos se halla atestiguada en esa zona desde mucho antes de generalizarse la apócope ${ }^{25}$, lo que dificulta pensar en una reposición en /i/de la vocal perdida y, desde luego, sería dilicilmente explicable desde un acusativo.

Parece, pues más acertada la explicación tradicional, frente a esta otra que, aunque estaría mås de acuerdo con la evolución morfológica teóricamente esperable, no atiende a estos datos antiguos ni a las necesidades, ya primitivas, de distinción entre los significantes.

En cuanto a las variantes formales que presenta a lo largo de la historia del castellano, hemos de decir que en la documentación medieval alternan indistintamente los resultados simples (este) y los derivados del refuerzo con "accu (aqueste< "accu iste), analógico del que recibe ille, y que acabará desapareciendo (al igual que aquese) por razones que veremos más adelante.

Ambas formas pueden aparecer apocopadas, de hecho, Lapesa señala que en los Doctumentos lingüisticos recopilados por Pidal estaquest prevalecen sobre este/aqueste liasta 1245 en que se generalizan los segundos: ${ }^{26}$

"...0 otro abad que venga pues dest" (Burgos, 1231; PIIN). (1966)). ${ }^{27}$

"in aquest mes"; "est otro"; "ad achest"; etc. (Auto R. Magos, LAPliSA (1979), 203).

24 I.APIESA (1979), páigs. 201-202.

${ }^{25}$ Concretamente, en los Documentos Lingiäslicos, se utestigua esli on la llioja desdo 1199 y 1209 , mientras qua est no figura hasta 1229 . La pujanza de esti es muy Fuerte de 1237 a 1254. Гecha on la que comionza a imponorse este (IAPliSA (1979), 204).

26. Las cilras concretas que expone Lapesa ((1979). prig. 203) son: años 11911213,12 est/5 este: $1215-1224,9$ est $/ 9$ este; $1227-1244,10$ est $/ 36$ este; desdo 1245 sólo este.

${ }^{27}$ MENIENDEZ PIDAL, It. (1966); Docnmentos lingüisticos de España, I, IR,F.E., Anojo LXXXIV, Madrid. 
"Si alguno de nros o de agenos est fecho que nos femos demudar..." (Sahagún, 1211; STMFi: (1907)). ${ }^{2 *}$

"Sabuda cosa sea a quantos que son por est escripto..." (Carrizo, 1251, C.Loisto (1983)). ${ }^{23}$

El Cantar de Mio Cid, en cambio, sỏlo registra dos lormas apocopadas, frente a más de una treintena de plenas: ${ }^{30}$

"a ella e a sus fijas e a sus dueñas

sirvádeslas est año" (v. 254).

"atal cavallo cum est" (v. 3518).

Aparecen frecuentemente en contracción con las preposiciones que los preceden:

"desta alma mezquina" (Berceo, Milagros, 14a).

"la tercia parte daquestas heredades ya dechas" (1249, C. Lolsato (1983), doc. 252).

"Et meto en nesta carta esta pena $\tau$ este coto" (Salamanca, 1272, ONIS $(1909))^{31}$.

Asimismo, en algunas zonas norteñas es frecuente que se documenten resultados en los que la /-e/ linal se ha cerrado en /-i/. Es un cierre muy común en la zona de la Rioja y norte de Castilla (Berceo), aunque también se da en åreas mås occidentales, como en zonas del leonés (oriente de Asturias o Liébana) $)^{32}$ :

2" STAMFF. I:. (1907); Elude sur l'ancien dialecte léonais d'aprés des chartes du XII/r siecle, Uppsala, Almquist-Wiksell, doc. VI (citado STAAFF (1907)).

29 CASADO LOBATO, C. (1983); Colección diplomática del Monasterio de Carrizo, T. I-II, Lcón. Contro de lestudios S.Isidoro, doc. 276 (citado C.LOBATO (198.3)).

3o Vid. IAPESA (1979), prig. 203; LAMIQUIZ (1967), peig. 168. Según datos de T. Montgomery ((1975); "La apócope en espuñol antiguo y la "i" final latina", Studia Ilispanica in honorem R.L.. III. 351-361, (citado MONTGOMERY)), también en la Fazienda de Uleramarse prefiere la forma este. MIENÉNDEZ PIDAI ${ }_{+}$R. (1969); Cantar de Mio Cid. Texto, Gramálica y Vocabulario, 1,Il,IIl, Madrid, Espasa-Calpo, 5ª ed., pág. 238 (citado PIDAl. (1969)).

${ }^{31}$ Los Milagros de Nuestra Señora, edic. do C. GAIrCfA TUIZA (1992); Obra completa de G. de Berceo, Madrid, Espasa-Calpe (citado Milagros). ON1S, F. do (1909); Contribución al estudio del dialecto leonés, Salumanca, doc. XVIII (citado ONIS $(1909))$.

32 Las explicaciones que so han dado para esta /.i/ son muy diversas: derivación diracta de la /-i/ final latina (Lıovo (1993), 336-337); analogía con la/-i/de QUl; tendenciu dialectal al cierre de las vocales útonas: reposición de la vocal tras la apöcope; otc. I apesa (1979), 204) haco notar que, tanto en la IRioja como en el norte de Castilla, osta /-i/ so halla atestiguada mucho antos quo las formas apocopadas, lo que dificulta pensar en une reposición de vocal perdida. Las formas con / $\mathrm{i} / \mathrm{son}$ antoriores a la apócope y, desde luego, corroboran la imposibilidad de la evolución desde a] acusalivo que proponen Alvar-Pottier. 
"Semeia esti prado"; "esti prado fue siempre verde" (Berceo, Milagros, $14 a, 20 a)$.

"Si algun omne esti pletu quisier crebantar sea maldictu..." (Piasca, 1229. StмғF (1907), doc. IX).

" $\tau$ arrendouolo dest $i$ Ssanto Martino que premero uion ata quatro annos conplidos... $\tau$ pol dicho rogo pusi en ella esti ssingno" (Asturias, 1294, C. Lовлто (1983), doc. 562).

III. 3.- Ese (esa, eso, esos, esas).

Procedente, en cuanto al significante, del antiguo pronombre de identidad latino ipse $^{33}$ que, como ya hemos visto, acaba ocupando en iberorromance el campo intermedio entre los resultados de iste e ille cuando se repone el sistema deictico de tres grados.

Pero esta situación delinitiva tardó mucho en estabilizarse y en los comienzos del romance encontramos usos de ipse (y de su derivado formal esse) que no son propiamente décticos. ${ }^{34}$

En el apartado de su evolución formal, además de la problemática, ya explicada, de su procedencia del nominativo o del acusativo, hemos de decir que su grafía en el castellano medieval lleva siempre "-ss-" (esse, essa, esso, etc.), como corresponde al resultado sordo /s/ de la asimilación de /-ps-/.

Al igual que en el caso de este, en la documentación medieval alternan indistintamente los resultados simples (esse) y los derivados del reftuerzo con *accu (aques(s)e< *accu ipse). ${ }^{35}$

También ambas formas pueden aparecer apocopadas. Lapesa señala es como la única forma que se documenta en el Cid, tanto ante vocal como ante consonante: "Es dia es salido" (v.1699); "En es alcaz" (v. 1147). ${ }^{\text {th }}$

En los Documentos lingüísticos, la forma plena es(s)e es minoritaria respecto a la apocopada durante la primera mitad del S.XIII y durante todo el siglo en los textos castellanos norteños:

"aqes logar" (LAPESA (1979), 203).

“... $\tau$ que procure es dia alos monges $\tau$ alos clerigos $\tau$ alos frayres de pan

${ }^{33}$ Etimología con la que no está de acuordo M. lübke ((1895); Grammaire des langues romanes, T. I-II-III, H. Welter (ed.), Paris, T. I, $\$ 458$ (citado M. IÜBKE (1895)), que considera que el resultado de $p s>i s>5$. Esse procedería de este reducido a es ante consonante, mientras que de ipse procedería la forma antigua exe, resultado que, según StaafT no se documenta en ningún texto castallano. Las posturas en contra de la hipoitesis do M. Lübke son recogidas por Staarf (1907, pág. 273).

34 Vid. M. Pidal (1980), pæig. 259; M. PlDAL (1986); Origenes del español (1950ग), Madrid, Espasa-Calpe, 10" ed., pég. 348 (citado M. PIDAL (1986)); V. Lamíquiz, (1967), pảg. 181; Alvar-Pottier (1983), pág. 105.

${ }^{35}$ Aunque sin duda se documentan estats formas compuestas, su frecuencia es mucho menor que la de aqueste. V. Lamíquiz (1967, págs. 174-75) destaca que en los primeros 500 versos del Cid sólo aparece en una ocaslón y en 400 versos del Libro de Buen Amor (estrofas 600 a 700 ) no se registra ninguna.

36 LAPESA(1979), pág. 203. 
t de uino..." (Piasca, 1282, Stamfl: (1907), doc. LXVI).

*...esta conpra fu fecha en es mismo dia $\tau$ en esa misma hora $\tau$ en esse mismo lugar $\tau$ delante esos mismos omres" (1258, ONIS (1909), doc. XI).

"... $\tau$ dobre es suclo eno [...] lugar" (1266, C. Loвnтo (1983), doc. 417).

También aparece en contracción con las preposiciones que lo preceden:

“...del solar desa casa..." (1253, C. Loßuтo (1983), doc. 295).

"El outra uina yaz enes mismo lugar" (1257, C. LoBATo (1983), doc 315).

Asimismo, en zonas norteñas se documentan resultados con /-i/ linal:

"...el convento desi mismo lugar" (Rioseco, 1285; M. PipA. (1966), 101).

"las dueñas essi dia fincamos" (Berceo, Duelo de la Virgen, 163a). ${ }^{37}$

III. 4.- Aquel (aquella, aquello, aquellos, aquellas).

a) Procedente del demostrativo latino ille, aunque modificado por el refuerzo que hemos visto también en aqueste, aquese. Como ya indicábamos páginas atrais, en el sistema binario protorromance, ille sería, con iste, el otro elemento de la oposicion, asociado al valor de "lejanía". Cuando se retoma la triple distinción, pasará de nuevo, aunque con significante modificado, a señalar la esfera de la tercera persona (o del "no yo", "no tú").

En cuanto a sus rasgos formales, el refuerzo que toma en castellano para llegar al resultado aquel (y, paralelamente, el de las variantes medievales aqueste, aquese) ha sido explicado de diversas maneras. ${ }^{3 .}$

Una gran parte de los investigadores están de acuerdo en suponer que se trataría de *accu, variante vulgar del adverbio con significado deíctico ecce, reconstruida a partir de los resultados romances. ${ }^{39}$

Sin embargo, esta variante no está documentada y tampoco se ha explicado de forma convincente el cambio de ecce en accu $u^{40}$, por lo que, otros autores, han propuesto explicaciones que se separan de las dos más generalizadas ("accu, eccu).

${ }^{37}$ Duelo de la Virgen, edic. de C. GARCIA TUIZA (1992); Obra completa de G. de Berceo, Madrid, Espusa-Calpe (citado Duelo).

${ }^{38}$ Ya vimos en su momento que estos refuerzos se generalizan ya on latín tardio para todo el sistema déictico, quizí por el desgaste que estabar sufriendo estas formas tanto en su significante como en sus valores. Ejemplos do ellos aparecon en todas las lenguas romances (rum. acesl; it. questo; fi. cehti-ci; etc.), lo cual corrobora que se trata de una evolución originada en el propio latín.

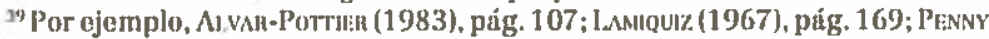
(1993); Gramálica histórica del español, Barcelona, Ariel, pág. 145 (citado PENNY (1993)). Otros como Hanssen ((1913); Gramática histörica de la lengua castellana, Halle, Max Niemoyer, pág. 84 (cilado HANSSEN (1913)), lordan-Manoliu (1972,301), M. Pjdal (1980, 260) o Cano Aguilar (1988, 143) parten de "eccu.

40 Tampoco los autores que parten de eccu explican la presencia da la /a-/ inicial, no etimológica segün ol punto de partida fijado. Algunos intentos do explicación son expuestos por F. Gonzilez Ollé (1977): "Precisiones sobre la etimología de aquel ${ }^{*}$, Jomenaje Prof. Muñoz Cortés, II, 863-869, pảgs, 864-65 (citado OLLÉ (1977)). 
Meyer-Lübke, a la vista de que las formas con /-a/ se extienden, según sus informaciones, por toda la Romania, postula el étimo común atque ille, del cual asegura que hay ejemplos desde tiempos de la República romana, pero no logra documentar su existencia. ${ }^{41}$

F. González Ollé retoma la idea del posible influjo de atque. En concreto parte de dos formaciones *atque ille o *alque eccum ille. El problema que plantean es que ninguna de las dos está documentada pero, "puesto que se documentan atque eccum y eccum ille. se ofrece como verosímil la existencia de "atque eccum ille; en cuanto que otros pronombres (ipse, is) conocen su reforzamiento por medio de atque, lo mismo puede acontecer a ille,[...] de modo que no resulta injustificado postular la existencia de *atque ille".

Partiendo de estas dos supuestas bases ( ${ }^{*}$ atque ille, "atque eccum ille), González Ollé intenta explicar el proceso evolutivo hasta aquel. La evolución de *atque eccum ille llegaria, tras un proceso normal a una secuencia del tipo */ak(w)ek(w)el/, que resultaría */akekel/. En este estadio fonético, por haplologia, se pudo eliminar la reiteración de una misma silaba, siendo el resultado final /akel/:

*atque eccum ille > */ak(w)ek(w)el/ > */akekel/ > /akel/.

El desarrollo fonético de "atque ille hasta aquel plantearia aún menos problemas ya que tendriamos */ak(w)el/s/akel/sin necesidad de recurrir a la haplología:

*atque ille > */ak(w)el/ > /akel/.

Como conclusión, pues, este autor destaca que: "tanto *atque eccum ille como "atque ille pueden considerarse, sin ninguna dificultad en el aspecto fonético igual que en el morfológico y sintáctico, étimos de aquel. Ambos presentan, sin embargo, el problema de su indocumentación [...]. Por el contrario, eccum ille debe ser desechado como étimo de aquel. Partir de este étimo obliga a suponer la inlluencia extrinseca de atque ${ }^{42}$. Previamente, para justificar ésta, debe admitirse que atque desempeñaba la misma función que eccum, es decir, concurría en formaciones como las citadas. En cuyo caso, el espontáneo desarrollo fonético de éstas resulta suliciente para llegar a aquel. sin necesidad de inllujos, cruces, etc ${ }^{n+3}$.

4' M. LÜBKE (1895), 1I, påg. 646.

22 Del influjo o cruce de eccum con atque surgiria, según autores como Dámaso Alonso, la forma *accu con la /a-/ necesaria para explicar aquel. Por otro lado, G. Ollé hace notar que Bastardas no registra eccu(m) ille en los documentos latinos españoles de los siglos VIII al IX; otro dato más para dudar do que se trate del śtimo adecuado.

${ }^{43}$ Vid. OLLÉ (1977), päg. 868. 
En resumen, tenemos:

$$
\begin{aligned}
& \text { T. tradicional - *aceu (<ecce) + ille } \\
& \text { Meyer-Lübke - "atque + ille } \\
& \text { AQUEL < } \\
& \text { G. Ollé }\left[\begin{array}{l}
\text { "atque eccum ille > } / \mathrm{ak}(\text { w)ek(w)el/s } \\
\text { "/akekel/ > /akel/. } \\
{ }^{*} \text { atque ille > */ak(w)el/ > /akel. }
\end{array}\right.
\end{aligned}
$$

Por nuestra parte, consideramos que, aunque la hipótesis de G. Ollé está bien construida, le falta el apoyo de la documentación. A pesar de que esta tampoco es muy segura en el caso de eccu/accu, el registro en el latín tardío de demostrativos reforzados con ecce, y con valor déctico, es más abundante que los casos en los que aparecen precedidos de atque (Atque illi (Plauto); atque ista (Ciccrón)). Además, en casi todos ellos, el valor de atque sigue siendo conjuntivo. Hasta no disponer de mús datos que conlirmen la construcción *atque ille con valor deíctico, no parece conveniente desechar la etimología tradicional, a pesar de la mal explicada presencia de /a- $\%$

b) Si dejamos de lado la cuestión del étimo, quedaría aún un aspecto pendiente de explicación. El refuerzo que toma ille se utiliza también en castellano antiguo para toda la serie del demostrativo, con la diferencia de que, mientras en aqueste y aquese el refuerzo fue ocasional y terminaría por perderse ${ }^{44}$, en el caso de ille se generalizó tempranamente y desplazó a la forma no incrementada. En otras lenguas románicas el refuerzo ha acabado por generalizarse a toda la serie (it. questo, codesto, quello; rum. acesta. acela; etc.).

La razón de que en castellano desuparezca el refuerzo para los dos primeros grados y se mantenga en el tercero quizá esté en la enorme productividad que caracteriza al latín ille en romance.

Si partimos de la serie completa tenemos: este/aqueste; ese/aquese; eV aquel. Los dos primeros, usen una variante u otra, no pueden confundirse con otros signilicados que no sean el deíctico. Sin embargo en el tercer grado podría confundirse con los otros resultados a los que da lugar el ille latino: cuando funcionara como pronombre (tónico, por tanto) con el pronombre personal de tercera persona; cuando lo hiciera como adjetivo (átono) con el articulo.

Así las cosas, la generalización de la variante reforzada no se trataba de una mera elección estilística o expresiva, sino de un rasgo pertinente para

44 A pesar de que ya desde el S. XIV so observa clara la tendencia a su eliminación, la doble serie se mantiene en los últimos años del $S$. XV, incluso Nebrija la racoge en su Gramálica. Continúa aún en el S. XVI pero Valdés en el Diálogo so refiere a ella con desagrado; el mismo Valdés no emplea en su obra mís que la serie de formas simples referentes al primer y segundo grado (Luiloulz (1967), 175-76). 
poder diferenciar la deixis de los otros contenidos para los que usaba la misma forma. La generalización de accu + ille permite a la lengua utilizar la forma simple como significante de los otros dos valores. Es necesario, pues, explicar esta forma del demostrativo en el marco más amplio del reajuste que sulren los resultados de ille.

Así lo resumen V. Lamíquiz: "uso exclusivo de las formas reforzadas de ille: aquel y sus variantes de género y número. Es normal para diferenciarlo del artículo y del pronombre personal, derivados del mismo étimo"; 0 Iso Echegoyen: ${ }^{45}$ "en español antiguo aparecen las formas analógicas aqueste aquese; en el moderno se vuelve, con este. ese a lo que debió ser al estadio primero...Naturalmente en esta lengua no aparece nunca una forma $e l$ como deíctico de $3^{\mathrm{n}}$ persona, pues esto hubiese arruinado la independencia del fórico pronominal él, que con tanto esfuerzo surgió en protorromance". th

Fuera de estos aspectos, aquel presenta las mismas dudas de etimología (nominativo o acusativo) que el resto de la serie y una evolución regular:

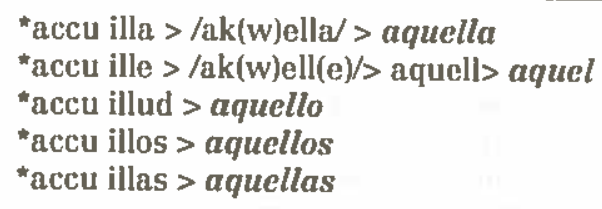

c) Respecto a las variantes formales que aparecen a lo largo de su historia, Lapesa destaca el resulado aquelle ("en aquelle logar"), sin apocopar en la Fazienda de Ultramar y en un documento de 1231 de Burgos; en al resto de textos que analiza, todos los resultados son apocopados (aquel, achel). Al igual que ocurre con los otros demostrativos, en documentos riojanos $y$, por supuesto, en Berceo se encuentra el resultado no apocopado, pero con /-i/ linal aquelli ${ }^{47}$ :

“...y vido a su padre, que llamavan Garçia

aquelli que non quiso seguir nula folia" (Berceo, Santa Oria, 85d).

III. 5. - Algunos valores y funciones de los demostrativos en época antigua

a) Se suele señalar con bastante frecuencia que los demostrativos, en goneral, y esse en particular, aparecen esporádicamente en los primeros textos castellanos con un valor cercano al artículo. M. Pidal destaca en el Cantar de Mio Cid valores tan atenuados de los demostrativos que "vengan a quedar como simples artículos, restos, sin duda, de la época anterior al triunfo completo de ille para el artículo". El uso de los demostrativos con

4" LAMIQUIZ (1967), püg. 174; I. ECIIIZGOYEN (1974), nota 14.

46 También Alvah-Potriri (1983), pág. 108.

\$7 LAPESA (1979), pägs. 202-204 y M. PIDAL (1980), píg. 260. 
este valor aparece en todo tipo de textos, pero es especialmente significativo en la poesía ćpica: ${ }^{48}$

"ego Didacus Gonzaluiz cum meis filiis...damua a aquela nina Urraca Gonzaluiz et ad Fernan Gonzaluiz meos criados...aquel ferrenal que iaze cabe Martin Iohanis" (1222, PIDA. (1966), 329).

"essa yent christiana" (Berceo, S. Domingo, 106c). $4 "$

"eche mano el querelloso en qual se quisiere daquellos...et aquel querelloso prenda qual se quisiere por enemigo" (PIDAL, 1966, 329).

"essos christianos" (Cid; 797, 800, 1236, 2346).

"es dia es salido" (Cid, 1699).

"Grado a Dios del çielo e aquel rey don Alfons" (Cid, 3452).

"maldize essa hora en que nasçiste" (Egipciaca, 121. PIDAL (1969)).

"mio Çid aguijó....con estos cavalleros quel sirven a so sabor" (Cid, 234)

Sin embargo, no todos los autores ven tan claro ese valor. R. Lapesa concretamente rechaza que los demostrativos así usados estén sustituyendo a artículos: "Indudablemente esta machacona insistencia en el señalamiento no responde al gusto moderno; para nosotros bastaría con usar el artículo. Pero esto no quiere decir, ni mucho menos, que los demostrativos tuvieran papel de artículo en la lengua antigua". "Lo difícil es admitir que la función de artículo existiera sin estar vinculada a un instrumento único. Más bien parece que el arcaísmo épico no consiste aquí en valerse de los demostrativos como artículos, sino en emplearlos mucho más liberalmente que hoy, prolongando el desbordamiento expresivo surgido en el latín vulgar. La diferencia con el uso moderno no estribaba sólo en la mayor frecuencia de los demostrativos, sino tambien en la mayor amplitud del campo que se les concedia, lo que daba lugar a algunas interferencias con el área del artículo".

En su estudio examina en prolundidad los casos en los que parece verse más claramente este uso y llega a la conclusión de que: "Casi todos los demostrativos a los cuales se ha atribuido valor de artículo, tienen función deictica muy perceptible... En ningún caso es probable que hicieran de verdaderos artículos".

En algunos casos se trata de "simples mostraciones "ad oculos" en las que un personaje señala mediante el demostrativo a alguien o algo que está presente.

Muchos de los textos notariales se redactarian seguramente en el mismo lugar que describen y los demostrativos senalarian sus divisiones, etc.

Por otro lado, señala Lapesa que toda narración, y más siendo épica, pedía insistente juego de referencias que apuntase a lo narrado y cuando se mencionaban heclsos o circunstancias ya conocidos, el juglar solía advertir-

48 Tambión en estudios anteriores como Gessner, E., (1897), pig. 349 o MeYthLCвке, W., (1895) 141.

"Santa Oria y Santo Domingo, en G. TURZL (1992); Obra complela de G. de Berceo. 
lo sirviéndose de demostrativos anafóricos: "aquel Muño Gustioz", "este don Ierónimo".

Podemos encontrar que la anáfora es simulada y se emplean los demostrativos para dar por consabido lo que se cita por primera vez y, dice Lapesa textualmente, "crear así una intimidad entre el juglar y su público, supuestos partícipes de un mismo caudal de datos previos".

Finalmente nos podemos hallar ante demostrativos evocadores, necesarios para la vivificación de los relatos: el narrador instalado imaginativamente en la situación que cuenta, señala lo que ve con la fantasía para hacer que también lo vean sus oyentes.

En resumen, según Lapesa, casi todos los demostrativos en los que se ha querido ver valor de artículo tienen un valor deíctico muy perceptible: "...señalan seres y cosas que (a) se hallan a la vista o se dan por presentes. (b) o bien han sido mencionadas antes, (c) o bien se relacionan con circunstancias de la situación, pertenecen a ella. A veces los demostrativos tienen clara intencion evocadora o son un artilugio para dar por consabido lo que no lo está...Lo que se dio en las narraciones medievales y en el Romancero fue la manifestación literaria más valiosa de las tendencias expresivistas que poblaron de demostrativos la frase latino-vulgar ${ }^{*} 30$.

b) Para este autor sólo se puede hablar de debilitación o atenuación significativa de los demostrativos cuando estos acompañan al nombre antecedente de un relativo. En tal ocasión conservan la función deictica, pero no es raro verlos desprovistos de su respectiva connotación de lugar, de su referencia a la persona gramatical correspondiente o de la noción de identidad, convertidos en mera señal anuncialdora del relativo. Por ejemplo, en casos como los siguientes:

\section{"pasauan a Triana et a todas esas partes o se querien" ( $P$. Crónica General). \\ "valié mas essi pueblo que la avié vecina" (Milagros, 320). \\ "mio Cid aguijó ...con estos cavalleros quel sirven a so sabor" (Cid, 234). \\ no se indica cercania al emisor ni al interlocutor, ni hay indicación previa o posterior de lo que señalan esos demostrativos.}

IV. Hasta aqui hemos intentado describir, el proceso evolutivo que experimentó el paradigma del demostrativo en castellano. Partiendo, como es lógico de los estadios latino y prerromance, encontramos el germen y la explicación de muchas de las mutaciones semánticas y formales que fueron fijando estas unidades en lo que hoy son: un paradigma cerrado que se caracteriza a) Formalmente, por ser elementos compuestos por un signo léxico y un signo morfológico que se corresponde con los contenidos de "género" y "número"; b) Funcionalmente, por pertenecer a la categoría de los adjetivos y, dentro de esta, a los determinativos; c) Semánticamente, por

${ }^{50}$ LAPESA (1979), págs. 37-42. 
combinar la noción de 'deixis' con la de 'persona $1^{\mathrm{a}}, 2^{\mathrm{a}}$ y $3^{\text {a51 }}$.

Nos hemos centrado en la época de origenes de nuestra lengua, aquella que muestra más vacilación formal y semántica. Somos conscientes de que un estudio de este tipo debe abarcar también periodos posteriores, las obvias limitacionos de espacio nos impiden hacerlo ahora; serán tema para un próximo trabajo.

\section{BIBLIOGRAFIA}

ABEL, F. (1971); L'adjectif démonstratif dans la langue de la Bible Latine. Etude sur la formation des systèmes déictiques et de l'article défini des langues romanes, Beihefte zur $\mathrm{Zr}, \mathrm{Ph} 125$, Tübingen, Nicmeyer. AEBISCHER, P. (1948); "Contribution à la protohistoire des articles ille et ipse dabs les langues romanes", Cultura Neolatina, VIII, 181-203.

ALARCOS LLORACII, E. (1972); Gramática estructural, Madrid, Gredos.

ALARCOS LLORACI, E. (1980); "Los demostrativos en español" en Estudios de gramática funcional del español (1970). Madrid, Gredos, 287 306.

ALARCOS LLORACH, E. (1990): Indefinidos y numerales, Lecciones de Lingüística y Didáctica del Español, 5, Consejería de Cultura y Deportes de la Rioja, Logroño.

ALARCOS LlORACH, E. (1994); Gramática de la lengua española, RAE, Madrid, Espasa-Calpe.

ALCINA, J.-BLECUA, J.M. (1975); Gramática española, Barcelonn, Ariel.

ALONSO, A. (1967); "Estilística y gramática del artículo en español", Estudios lingüísticos. Temas españoles, Madrid, Gredos, 125-160.

ALONSO, A.-H. UREÑA, P. (1969); Gramatica castellana, Buenos Aires, Losada.

ALVAR EZQUERRA, M. (1979); "El determinante", LEA, 1/1, 31-66.

ALVAR, M.-POT"TIER, B. (1983); Morfologia histórica del español, Mudrid, Gredos.

ALVAREZ MARTINEZ, $\mathrm{M}^{\mathrm{n}}$.A. (1986a); El articulo como entidad funcional en el español de hoy, Madrid, Gredos.

ALVAREZ MARTINEZ, M" ${ }^{\mathrm{n}}$.A. (1986b); "Dos aspectos del funcionamiento del relativo", RSEL, 16, 113-131.

ALVAREZ MARTINEZ, $\mathrm{M}^{\mathrm{n}}$.A. (1989); El pronombre I. Personales, articulo. demostrativos, posesivos, Madrid, Arco Libros.

BADIA MARGARIT, A. (1952); "Los demostrativos y los verbos de movimiento en ibororrománico", Estudios dedicados a Menéndez pidal, IIl, 3-31.

BARRENECHEA, A. M"MANACORDA DE ROSETTI, M.V. (1975); Estudios de gramática estructural, Buenos Aires, Paidós.

BARTOS, L. (1978); "Notas a la clasificación del adjetivo", Estudios ofrecidos a E. Alarcos Llorach, II, 45-60.

5I Vid. ALAliCOS (1994); Gramatica de la lengua española, RAE, Madrid, Espasa-Calpe. págs. 82-84 y 88-92. 
BASSOLS DE CLIMENT, M. (1981); Sintaxis latina, I-II (1956), Madrid, C.S.I.C.

BELLO, A. (1981) Gramática de la lengua castellana (1847). Ed. de R. Trujillo, Cabildo de Tenerife.

BENVENISTE, E. (1977); Problemas de lingüistica general 1-II, Madrid, Siglo XXI.

BERNARDEZ, E. (1982); Introducción a la lingüistica del texto, Madrid, Espasa-Calpe.

BOSQUE, I. (1983); "Clases de nombres comunes", Serta Philológica F. Läzaro Carreter, I, 75-88.

BOSQUE, I. (1983a); “Determinantes y cuantificadores: Artículo, posesivos, indefinidos, numerales, etc.", Problemas de morfosintaxis. Ejercicios de gramática española para estudiantes universitarios, Universidad Complutense, 43-55.

B0SQUE, I. (1989); Las categorias gramaticales, Madrid, Sintesis.

BOUVIER, E. (1972); "Le demonstratif latin ille et la formation de l'article défini des langues romanes", Cahiers de Lexicologie, 21, 2, 75-86.

BOVES NAVES, M. (1972); "La coordinación en la frase nominal castellana", RSEL, 2, 215-311.

BRIZ GOMEZ, A. (1989); Sustantivación y lexicalización en español (la incidencia del articulo), Cuadernos de Filología, Anejo IV, Universitat de València.

BÜHLER, K. (1979); Teoria del lenguaje (1950), Madrid, Alianza Editorial.

BUSTOS, E. (1984); “Lâ dimensión pragmática de las expresiones cuantificacionales clásicas del castellano", Contextos, II/4, 73-85.

CANO AGUILAR, R. (1988); El español a través de los tiempos, Madrid, Arco Libros.

CARNOY . A.J. (1983); Le latin d'Espagne d'après les inscriptions (1906), Hildesheim, Georg 0lms.

CASADO LOBATO, C. (1983); Colección diplomática del Monasterio de Carrizo, T. I-II, León, Centro de Estudios S.Isidoro.

CliARAUDEAU, P. (1970); "Les démonstratif́s", Description sémantique de quelques systèmes grammaticaux de l'espagnolactuel, Paris, Centre de Documentation Universitaire, 47-55.

CIFUENTES, J. L. (1989); Lengua y espacio. Introducción al problema de la deixis. Universidad de Alicante.

CODOÑER, C. (1973); "Introducción al estudio de los demostrativos latinos", R.E.L., 3/1, 81-93.

CONTRERAS, H.(1968); "The Structure of the Determiner in Spanish", Linguistics, 44, 22-28.

CORBLIN, F, (1987); Indéfini, défini et démonstratif. Constructions linguistiques de la référence, Langue et Culture 17, Genève, Libraire Droz.

COSERIU, E. (1969); "Determinación y entorno", Teoria del lenguaje y lingüistica general, Madrid, Gredos, 282-323.

DIAZ Y DIAZ, M. (1962); Antologia del latín vulgar, Mdrid, Gredos. 
DIETRICK, D. (1988); "Aproximaciốn al sistema y uso de los demostrativos en español", Anuario de Lingüística hispánica, 4, 99-113.

ENRIQUEZ, E.V. (1985); "Nuevos datos en torno al tercer elemento del campo deíctico de la persona", Archivo de Filología Aragonesa, XXXVI-XXXVII, 149-171.

ERNOUT, A.-THOMAS, F. (1972); Syntaxe latine (1953), Paris, Klineksieck. FERNANDEZ RAMIREZ, S. (1987); Gramática Española. El Pronombre (1951). Volumen preparado por J. Polo, Madrid, Arco Libros.

FONTAN, A. (1965); "Historia y sistemas de los demostrativos latinos", Emérita. XXXIII/1, 71-107.

FUENTES RODRIGUEZ, C. (1989); "El adyacente nominal”, Analecta Malacilana, XII, 2, 243-263.

GAMILLSCHEG, E. (1937); "Zur romanischen Artikel und Possessivpronomen", En E. Gamillscheg Ausgewählte Aufsälze, Jena-Leipzig. W. Gronau, 43-78.

GARRIDO MEDINA, J. (1991); Elementos de análisis lingüistico, Madrid, Fundamentos.

GESSNER, E. (1897): "Das spanische Possessiv und Demonstrativpronomen" $Z R P h . X X I, 329-346$.

GONZALEZ CALVO, J.M. (1979); "El género, ¿una categoria morfológica?". Anuario de Estudios Filológicos, II, 51-73.

GONZALEZ CALVO, J.M. (1981); "Sobre el adjetivo como clase de palabras independiente en español”. Anuario de Estudios Filológicos, IV, 115127.

GONZALEZ LUIS, J. (1990); “La evolución de ille hasta la creación del artículo en las lenguas románicas", Actas del Congreso de la SEL, XX Aniversario, 199-205.

GONZALEZ OLLE, F. (1977); "Precisiones sobre la etimología de aquel", Homenaje Prof. Muñoz Cortés, II, 863-869.

GONZALO DE BERCEO; Obra completa, Madrid, Espusa-Calpe, 1992.

GUTIERREZ ORDON̄EZ, S. (1981); Lingüística y Semäntica, Universidad de Oviedo.

GuTierREZ ondoN̄EZ, S. (1985); "Sobre las Categorias, las Clases y la Transposición", Contextos, IIL/5, 75-111.

GUTIERREZ ORDON̄EZ, S. (1986); Variaciones sobre la Atribución, Colección Contextos, 5, Univers. de León.

GUTIERREZ ORDON̄EZ, S. (1989); Introducción a la Semántica funcional, Madrid, Sintesis.

GUTIERREZ ORDOÑEZ, S. (1993); Curso de Pragmática, Recopilación de temus inéditos explicados en la Universidad de León.

HANSSEN, F. (1913); Gramática histórica de la lengua castellana, Halle, Max Niemeyer.

HERNANDEZ ALONSO, C. (1992): “El morfema de número en español”, Gramma-Temas, Col Contextos, 145-160.

HERNANDEZ, C.(1985); “enles, ennes", R.F.E., 1XV, 317- 318. 
IORDAN, I.-MANOLIU, M. (1972); Manual de Lingüistica románica, I-II, Madrid, Gredos.

ISO ECHEGOYEN, J.J. (1974); " En torno al sistema deíctico pronominal en latín y su paso a las lenguas románicas", R.L.L., 4/2, 459-471.

KLEIBER, G. (1986); " $A$ propos de l'analyse "adjectif demostratif= article défini + élément dèictique" ou sur l'irréductibilité des symboles indexicaux", Actes XVII CILPhR, IV, 193-212.

KOCK, J. de (1988); "Este, ese y aquel" en el español escrito", Homenaje a A. Zamora Vicente, I, 411-425.

LAMIQUIZ, V. (1967); "El demostrativo en español y en francés: estudio comparativo y estructuración”, R.F.E., L, 163-202.

LAPESA, R. (1961); "Del demostrativo al artículo", N.R.F.II., XV, 23-44.

LAPESA, R. (1976); Dos estudios sobre la actualización del sustantivo en español, Madrid.

LAPESA, R. (1979); "Nominativo o caso oblicuo latinos como origen de demostrativos y artículo castellanos", F. Kurt Baldinger, 196-207.

LAPESA, R. (1984): "El neutro en calificativos y determinativos castellanos”, Estudis en memòria $M$. Sanchis Guarner, II, 173-187.

LAUSBERG, H. (1964); Linguiística románica, I-II, Madrid, Gredos.

LAZARO CARRETER, F. (1964); "Problemas de terminología lingüística", Presente y futuro de la Lengua Española, II, Cultura Hispainica, Madrid, 383-392.

LERCH, E. (1940); "Gibt es im Vulgärlat. oder im Rimän. eine "Gelenkspartikel"?", $Z R P h, L X, 113-190$.

LEVINSON, S. (1983); Pragmática, Barcelona, Teide, 1989.

LLOYD. P. (1993); Del latín al español, Madrid, Gredos.

LOFFTEDT, E. (1942); "Zur Vorgeschichte des romanischen Artikels", Syntactica, I, cap.XIX, Lund-Leipzig-London.

LUJAN, M. (1980); Semántica y sintaxis del adjetivo, Madrid, Caitedra.

LYONS, J. (1980); Semántica, versión española de R. Cerdá, Barcelona, Teide.

MARTINEZ, J.A. (1981 -82); "Acerca de la transposición y el aditamento sin preposición”, Archivum, XXXI-XXXIl, Oviedo, 493-512.

MARTINEZ, J.A. (1989); El Pronombre (II). Numerales, Indefinidos y Relativos, Madrid, Arco Libros.

MENENDEZ PIDAL., R. (1966); Documentos lingütusticos de España, I, R.F.E., Anejo LXXXIV, Madrid.

MENENDEZ PIDAL, R. (1969); Cantar de Mio Cid. Texto, Gramática y Vocabulario, I,II,III, Madrid, Espasa-Calpe, $5^{\mathrm{a}} \mathrm{ed}$.

MENENDEZ PIDAL, R. (1980); Manual de Gramática histórica española (1940), Madrid, Espasa-Calpe, $16^{\mathrm{a}} \mathrm{ed.}$

MENENDEZ PIDAL, R. (1986); Orígenes del español (1950), Madrid, EspasıCalpe, $10^{\mathrm{a}} \mathrm{ed}$.

MEYER-LUBKE, W. (1895); Grammaire des langues romanes, T. I-II-III, H. Welter (ed.), Paris. 
MONTGOMERY, T. (1975); “La apócope en español antiguo y la "i” final latina", Studia Hispanica in honorem R.L., III, 351-361.

MORENO CABRERA, J.C. (1982); "Atribución, Ecuación y Especificación: tres aspectos de la semántica de la cópula en español", REL. 12,2, 230-245.

NAVAS RUIZ, R. (1977); "Sobre la clasilicación del adjetivo", Ser y Estar, Almar, Salamanca, 121-126.

ONIS, F. de (1909); Contribución al estudio del dialecto leonés, Salamanca. PENNY, R. (1993); Gramática histórica del español, Barcelona, Ariel.

PICOCHE, J. (1977); Précis de lexicologiefrançaise. L'étude et l'enseignement du vocabulaire, Paris, F. Nathan (ed.).

POEMA DE MIO CID; Ed. de Ian Michael, Madrid, Castalia, 1976.

PRADO IBAN, E. (1993); Los determinantes en español, Tesis doctoral publicada en microficha, Universidad de Leon.

R.A.E. (1931); Gramática de la lengua española, Madrid, Espasa-Calpe.

R.A.E. (1973); Esbozo de una nueva gramática de la lengua española, Madrid, Espasa-Calpe.

ROCA PONS, J. (1970); Introducción a la Gramática, Barcelona, Teide.

RODRIGUEZ DIEZ, B. (1992); "Los posesivos en español", Gramma-Temas, I, Col. Contextos, 215-230.

RODRIGUEZ DIEZ, B. (1992a); “Los cuantilicadores en español”, GrammaTemas, I, Col. Contextos, 231-255.

SAEZ, E.-SAEZ SANCHEZ, C. (1990); Colección Documental del Archivo de la Catedral de León (775-1230), Il (953-985), León, Centro de Estudios S.Isidoro (cit. CAT. LEON).

STAAFF, E. (1907); Etude sur l'ancien dialecte léonais d'aprés des chartes du XIIr siècle, Uppsala, Almquist-Wiksell.

SUÑER, M. (1982); Syntax and Semantics of Spanish Presentational Sentence-Types, Washington D.C., Georgetown University Press.

TESO, E. del (1989); "La indeterminación de los nombres propios", ContexLos, VIV/14, 123-149.

TRAGER, G.L. (1932); The use of the latin demonstratives (specially "ille" and "ipse") up to 600 a.D., as the source of the Romance article, New York.

VÄÄNÄNEN, V. (1975); Introducción al latín vulgar (1967), Madrid, Gredos.

VERA LUJAN, A. (1979-80); "Los adjetivos deícticos en español", Anales de la Universidad de Murcia, XXXVIII, 1, 159-176.

WARTBURG, W. v. (1951); Problemas y métodos de la lingiïstica (1943), CSIC, Madrid ( $2^{n}$ ed. en colab. S. Ullmann, Ein/hrung in Problematik und Methodik der Sprachwissensch, Tubinga, 1962). 